\title{
Clinical outcome of laparoscopic distal pancreatectomy
}

\author{
Yoshiharu Nakamura · Eiji Uchida - Takayuki Aimoto • \\ Satoshi Matsumoto $\cdot$ Hiroshi Yoshida - Takashi Tajiri
}

Received: 6 December 2007 / Accepted: 15 January 2008/Published online: 16 December 2008

(C) Springer 2008

\begin{abstract}
Background Few studies have compared laparoscopic distal pancreatectomy (Lap-DP) and open distal pancreatectomy (open-DP). The aim of this study was to evaluate the clinical outcome of Lap-DP and compare it to that of open-DP.

Methods A total of 37 patients who underwent distal pancreatectomy (Lap-DP, 21 patients; open-DP, 16 patients) between January 2000 and March 2007 were enrolled in this study. Prior to January 2004, open-DP was the standard procedure for patients with a lesion in the distal pancreas without invasive ductal cancer; thereafter, Lap-DP was also an approved procedure. All 16 open-DP procedures were performed prior to January 2004.

Results The operating times for the Lap-DP and open-DP patients were $308.4 \pm 124.6$ and $281.5 \pm 83.3 \mathrm{~min}$, respectively, and these were not significantly different $(P=0.4635)$. Blood loss for the Lap-DP group $(249.0 \pm 239.8 \mathrm{ml})$ was significantly smaller than that for the open-DP group $(714.1 \pm 650.4 \mathrm{ml})(P=0.0055)$, and none of the patients in the Lap-DP group received transfusions. The frequency of complications for the Lap-DP and open-DP groups was 0 and $18.8 \%$, respectively, which is not significantly different $(P=0.0784)$. The average hospital stay for the Lap-DP group was significantly shorter than that for the open-DP group $(10.0 \pm 2.6$ vs. $25.8 \pm 8.8$ days; $P<0.0001)$.
\end{abstract}

Y. Nakamura $(\bowtie) \cdot$ E. Uchida · T. Aimoto - S. Matsumoto ·

H. Yoshida $\cdot$ T. Tajiri

Department of Surgery, Nippon Medical School,

1-1-5 Sendagi, Bunkyo-ku, Tokyo 113-8603, Japan

e-mail: keishun@nms.ac.jp
Conclusion In pancreatic diseases, other than invasive ductal cancer, arising in the distal pancreas, Lap-DP might be a more feasible and safer than open-DP.

Keywords Distal pancreatectomy ·

Laparoscopic distal pancreatectomy $\cdot$ Pancreas

\section{Introduction}

Laparoscopic surgery is widely performed because: (1) the surgical wound is small, and cosmetically favourable outcomes can be expected; (2) areas that cannot be seen with the naked eye can be clearly visualised using a laparoscope, allowing more detailed procedures and reducing blood loss; (3) less surgical invasiveness shortens the length of the postoperative stay, thus lowering costs. These advantages also apply to pancreatic diseases, and in recent years, there have been an increasing number of reports of laparoscopic distal pancreatectomy (Lap-DP) [1-24]. However, there have been few studies comparing Lap-DP and open distal pancreatectomy (open-DP). The purpose of this study was to evaluate the clinical outcome of Lap-DP in comparison to that of open-DP.

\section{Patients and methods}

We retrospectively reviewed the clinical charts of all 37 patients who had a lesion in the distal pancreas, excluding invasive ductal cancer, and who underwent either laparoscopic or open distal pancreatectomy at the Nippon Medical School Hospital from January 2000 to March 2007.

The Lap-DP and open-DP groups differ in terms of the period of time they were operated upon. Of the 37 patients, 
16 underwent open-DP during the first period of the study, from January 2000 to December 2003. Following the approval of the hospital's Ethics Review Board for the Lap-DP procedure, we performed laparoscopic distal pancreatectomy for all other 21 patients of our patient cohort, who gave informed written consent to undergo Lap-DP, in the second period of the study, from January 2004 until March 2007. Although Lap-DP was performed by one surgeon, open-DP was performed by this same surgeon as well as two other pancreatic surgeons.

The average age of the patients of the Lap-DP group was 54 years (range 14-76 years), and there were six men and 15 women, with an average body mass index (BMI) of $23.4 \mathrm{~kg} / \mathrm{m}^{2}$ (range $18.5-28.2 \mathrm{~kg} / \mathrm{m}^{2}$ ). The main tumour location was the pancreatic body $(\mathrm{Pb})$ in nine patients and the pancreatic tail $(\mathrm{Pt})$ in 12 patients. The average tumour size was $4.7 \mathrm{~cm}$ (range $1.5-13 \mathrm{~cm}$ ). Complications were seen in seven patients (colon cancer $n=4$, cholelithiasis $n=2$ and left adrenal gland tumour $n=1$ ), and these lesions were excised by simultaneous laparoscopic surgery. In all patients, conventional blood tests, chest radiography, electrocardiography, ultrasonography and computed tomography were performed. Endoscopic retrograde cholangio-pancreatography and endoscopic ultrasound scans were performed on selected patients. The spleen was also excised when a tumour was located in the Pt and was in close proximity with the spleen and splenic hilum, or when a tumour was malignant or metastatic. When the need for a splenectomy was present, pneumococcal vaccination was carried out preoperatively.

The final diagnosis was based on either a rapid pathological diagnosis or postoperative histopathological diagnosis. In the Lap-DP group, six patients had mucinous cystadenoma (MCA), four patients had an islet cell tumour, three patients had serous cystadenoma (SCA), two patients had a metastatic pancreatic tumour, two patients had an intrapancreatic spleen, one patient had a solid and pseudopapillary tumour (SPT), one patient had an intraductal papillary mucinous tumour (IPMT), one patient had a simple cyst and one patient had adenocarcinoma. In the open-DP group, four patients had MCA, two patients had an islet cell tumour, three patients had SCA, one patient had a metastatic pancreatic tumour, one patient had SPT, one patient had IPMT, one patient had a simple cyst and three patients had chronic pancreatitis (Table 1). In one patient in the Lap-DP group, rapid pathological diagnosis during the operation confirmed adenocarcinoma; as a result, Lap-DP was converted to open surgery. Therefore, we only compared the remaining 20 Lap-DP patients and 16 open-DP patients.

Pancreatic fistula was defined according to the 2005 International Study Group of Pancreatic Fistula [25, 26], and clinical leaks were classified into grades B and C.
Table 1 Final diagnosis of patients based on histopathology after distal pancreatectomy

\begin{tabular}{lll}
\hline Final clinical diagnosis & $\begin{array}{l}\text { Lap-DP } \\
\text { (no. of patients) }\end{array}$ & $\begin{array}{l}\text { Open-DP } \\
\text { (no. of patients) }\end{array}$ \\
\hline Mucinous cystadenoma & 6 & 4 \\
Islet cell tumour & 4 & 2 \\
Serous cystadenoma & 3 & 3 \\
Metastatic tumour & 2 & 1 \\
Intrapancreatic spleen & 2 & 0 \\
SPT & 1 & 1 \\
IPMT & 1 & 1 \\
Simple cyst & 1 & 1 \\
Chronic pancreatitis & 0 & 3 \\
Adenocarcinoma & $1^{\text {a }}$ & 0 \\
Total & 21 & 16 \\
\hline
\end{tabular}

Lap, Laparoscopic; DP, distal pancreatectomy; SPT, solid and pseudopapillary tumour; IPMT, intraductal papillary mucinous tumour

${ }^{\text {a }}$ Procedure in this patient was converted to open surgery

Statistical analysis was performed using the Statistical Package for Social Sciences (SPSS) ver. 12.0 (SPSS, Chicago, IL). Data are expressed as means \pm standard deviation (SD). Data from each period were compared by the unpaired $t$ test and Fisher's exact test, as appropriate. A correlation analysis of continuous variables was performed using Spearman's rank test. Probability $(P)$ values $<0.05$ were considered to be significant.

\section{Lap-DP procedure}

Each patient was immobilised in the right $45^{\circ}$ semirecumbent position and, with rotation of the operating table, patient angles were adjusted as needed. Depending on tumour size, four trocars were generally inserted into the following locations: the left side of the naval $(12 \mathrm{~mm})$; $5 \mathrm{~cm}$ caudal to the hypochondrium along the upper abdominal median line $(5 \mathrm{~mm})$; near the left mammillary line below the costal arch $(12 \mathrm{~mm})$; the anterior subcostal region-midaxillary line (12 mm) (Fig. 1). Abdominal air pressure was set at $7-10 \mathrm{mmHg}$.

After the omental bursa had been opened, intraoperative ultrasound was performed to determine the location of the tumour and pancreatic resection. In 19 of the 20 patients, the pancreas was resected using an endoscopic linear stapler (ELS) (EndoGIA-II 60-4.8; Tyco Japan, Tokyo, Japan). In the one remaining patient, laparoscopic coagulating shears (LCS) were used to cut the pancreas and ligate the main pancreatic duct. The pancreatic resection stump was not subjected to oversewing or fibrin glue application. 


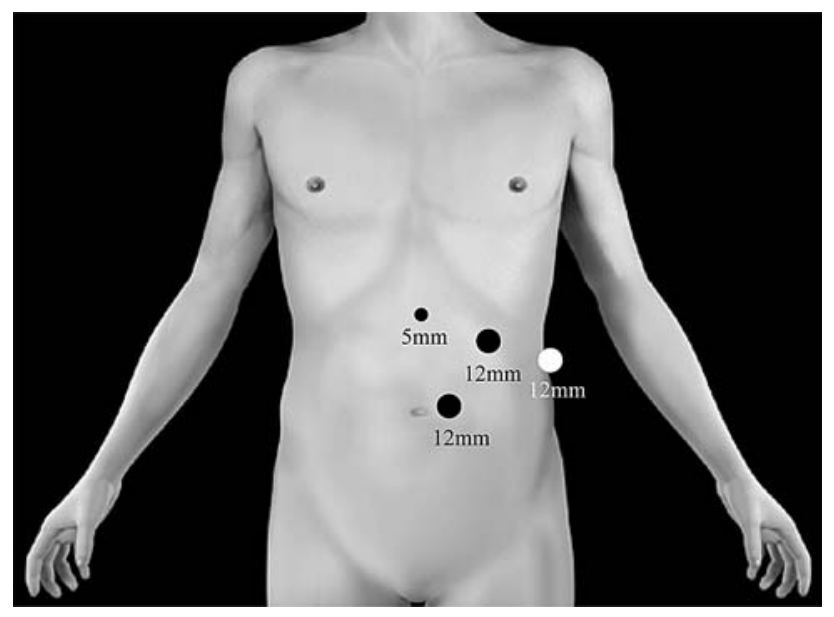

Fig. 1 Trocar placement for laparoscopic distal pancreatectomy

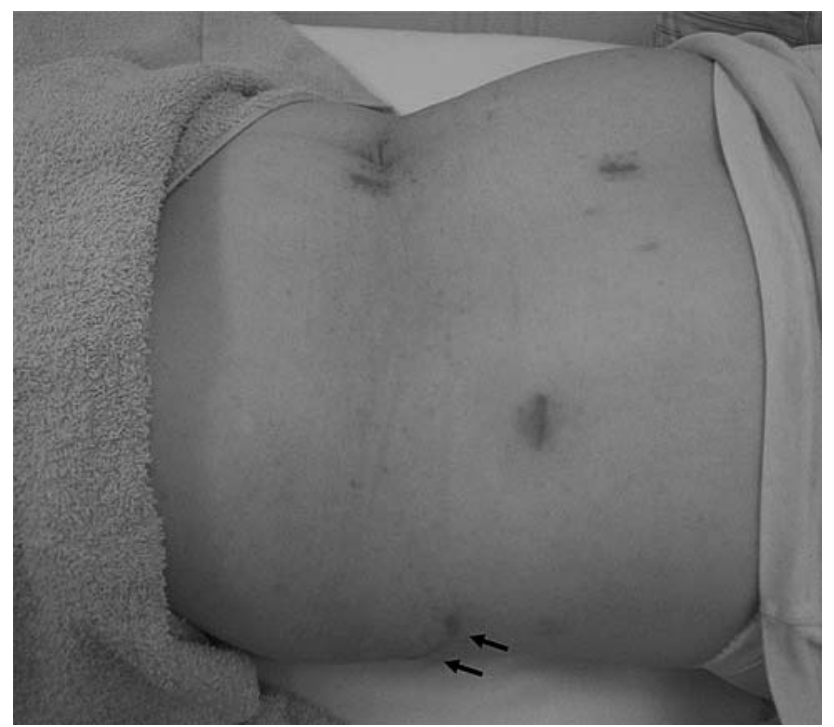

Fig. 2 Wound view after laparoscopic distal pancreatectomy with splenectomy. A small incision was made on the flank region (arrows), where the wound was less noticeable from the anterior view, in order to remove the resected tissue

The resected tissue was placed in a surgical bag (ENDOcatch II; Tyco Japan), and when the spleen was conserved, resected tissue was removed from where the trocar had been inserted. When the spleen was also resected, except for when Lap-DP was converted into a hand-assisted procedure (HAP), a small incision was made on the flank region, where the wound was less noticeable from the anterior view, so as to be able to remove the resected tissue (Fig. 2). When the spleen was conserved, the splenic artery and vein were conserved in all patients, and Warshaw and colleagues' procedure [27] was not employed.

\section{Open-DP procedure}

Each patient was placed in the supine position, and a median incision was made in the upper abdominal region; when the field of view was poor, a horizontal incision was placed on the left side. Pancreatic resection was performed using LCS in all patients, and the main pancreatic duct was ligated. The pancreatic stump remained open without oversewing or the application of fibrin glue. As was the case with Lap-DP, when the spleen was conserved, the splenic artery and vein were conserved in all cases.

\section{Results}

Because rapid intraoperative pathological diagnosis confirmed pancreatic cancer in one patient, Lap-DP was converted to open surgery; Lap-DP was completed in 20 patients. Of these 20 patients, the spleen was resected in 13 patients and conserved in seven patients. The Lap-DP was converted to HAP in five patients, including those in whom the splenic artery (SA) could not be found laparoscopically $(n=2)$ and those in whom the left pancreas and spleen were isolated laparoscopically, removed through a small wound, and subject to vascular procedures and pancreatic resection using $\operatorname{HAP}(n=3)$. All of these latter five patients were from the early stage of Lap-DP implementation. In 19 of the 20 patients, pancreatic resection was performed using only ELS. The Lap-DP was combined with other laparoscopic procedures in seven patients, including laparoscopic colectomy $(n=4)$, laparoscopic

Table 2 Procedure types in laparoscopic distal pancreatectomy

\begin{tabular}{ll}
\hline Procedures in Lap-DP & $\begin{array}{l}\text { Number of } \\
\text { patients }\end{array}$ \\
\hline Conversion of Lap-DP & $1 / 21$ \\
$\quad$ Conversion to open surgery & $5 / 20$ \\
$\quad$ Conversion to hand-assisted surgery & \\
DP involving spleen & $13 / 20$ \\
DP with splenectomy & $7 / 20$ \\
DP with spleen and splenic vessel preservation & \\
Method of pancreas transection & $19 / 20$ \\
Endoscopic linear stapler alone & $1 / 20$ \\
Laparoscopic coagulating shears + & \\
$\quad$ main pancreatic duct ligation & $7 / 20$ \\
Simultaneous surgery with Lap-DP & 4 \\
Laparoscopic colectomy for colon cancer & 2 \\
$\quad$ Laparoscopic cholecystectomy for cholelithiasis & 1 \\
Laparoscopic left adrenalectomy for adrenal tumour &
\end{tabular}

Lap-DP, Laparoscopic distal pancreatectomy 
Table 3 Comparison of 20 Lap-DP cases and 16 open-DP cases

\begin{tabular}{|c|c|c|c|}
\hline Demographic-clinical factors & Lap-DP (20 cases) & Open-DP (16 cases) & $P$ value \\
\hline Age, years ${ }^{\mathrm{a}}$ & $53.5 \pm 18.6$ & $61.5 \pm 20.6$ & $0.2294^{\mathrm{C}}$ \\
\hline Sex (male/female) & $6 / 14$ & $8 / 8$ & $0.3074^{\mathrm{C}}$ \\
\hline ASA physical status score ${ }^{a}$ & $1.8 \pm 0.6$ & $1.9 \pm 0.7$ & $0.5846^{\mathrm{C}}$ \\
\hline Body mass index, $\mathrm{kg} / \mathrm{m}^{2 \mathrm{a}}$ & $23.4 \pm 2.9$ & $21.3 \pm 4.2$ & $0.0789^{\mathrm{c}}$ \\
\hline Tumour location (no. of patients) & Pt $12, \mathrm{~Pb} 8$ & $\mathrm{Pt} 7, \mathrm{~Pb} 9$ & $0.5027^{\mathrm{C}}$ \\
\hline Tumour size, centimetres ${ }^{\mathrm{a}}$ & $4.8 \pm 3.3$ & $4.1 \pm 2.1$ & $0.5157^{\mathrm{C}}$ \\
\hline Spleen preservation (no. of patients) & 7 & 5 & $>0.9999^{\circ}$ \\
\hline Operation time, minutes ${ }^{\mathrm{a}}$ & $308.4 \pm 124.6$ & $281.5 \pm 83.3$ & $0.4635^{\mathrm{c}}$ \\
\hline Blood loss, millilitres $^{\mathrm{a}}$ & $249.0 \pm 239.8$ & $714.1 \pm 650.4$ & $0.0055^{\mathrm{c}}$ \\
\hline Blood transfusions (no. of patients) & 0 & 7 & $0.0014^{\mathrm{C}}$ \\
\hline Time to oral intake, days ${ }^{\mathrm{a}}$ & $2.4 \pm 1.1$ & $6.3 \pm 5.0$ & $0.0018^{\mathrm{c}}$ \\
\hline Time to first passage of flatus, days ${ }^{\mathrm{a}}$ & $1.9 \pm 0.9$ & $3.9 \pm 1.4$ & $<0.0001^{\mathrm{c}}$ \\
\hline Urinary tract catheterisation, days ${ }^{\mathrm{a}}$ & $2.3 \pm 1.3$ & $3.5 \pm 1.5$ & $0.0149^{\mathrm{c}}$ \\
\hline Complications (no. of patients) & 0 & 3 & $0.0784^{\mathrm{C}}$ \\
\hline Pancreatic fistula $(\text { Grade } \mathrm{B}, \mathrm{C})^{\mathrm{b}}$ & 0 & 2 & $0.1905^{\circ}$ \\
\hline Others & 0 & 1 & \\
\hline Postoperative hospital stay, days ${ }^{\mathrm{a}}$ & $10.0 \pm 2.6$ & $25.8 \pm 8.8$ & $<0.0001^{\mathrm{c}}$ \\
\hline
\end{tabular}

ASA, American Society of Anesthesiologists; Pt, pancreatic tail; $\mathrm{Pb}$, pancreatic body

${ }^{\text {a }}$ Expressed as mean \pm standard deviation

b According to International Study Group of Pancreatic Fistula

c Unpaired $t$-test

${ }^{\mathrm{d}}$ Fisher's exact test

cholecystectomy $(n=2)$, and laparoscopic left adrenalectomy $(n=1)$ (Table 2).

The postoperative data for the 20 Lap-DP patients, excluding the patient with conversion to open-DP, were as follows: median operating time was $280 \mathrm{~min}$ (range 150-635 min), and median blood loss was $200 \mathrm{ml}$ (range 10-1020 ml). No transfusions were given during or after surgery in any of the patients. In all patients, including those who underwent concurrent surgeries, oral intake was started within 5 days of surgery, and the median value was 2 days after surgery. There was no grade B or C pancreatic fistula, and there were no other postoperative complications. The median hospital stay was 9 days (range 6-15 days), and none of the patients died perioperatively.

Between the Lap-DP and open-DP groups, there were no significant intergroup differences in the following clinical factors: age, sex, American Society of Anesthesiologists physical status score, BMI, tumour location, tumour size and frequency of spleen conservation (Table 3 ). The average operating time for the Lap-DP and open-DP groups was $308.4 \pm 124.6$ and $281.5 \pm 83.3 \mathrm{~min}$, respectively, which is not a significant intergroup difference $(P=0.4635)$. The average blood loss for the Lap-DP and open-DP groups was $249.0 \pm 239.8$ and $714.1 \pm 650.4 \mathrm{ml}$, respectively, which is a significant intergroup difference $(P=0.0055)$. None of the patients in the Lap-DP group received transfusions
$(P=0.0014)$. The time to first passage of flatus after surgery for the Lap-DP and open-DP group was day $1.9 \pm 0.9$ and $3.9 \pm 1.4$, respectively, and there was a significant intergroup difference $(P<0.0001)$. The average time to oral intake after surgery for the Lap-DP group was $2.4 \pm 1.1$ days, which was significantly shorter than that of the open-DP group $(P=0.0018)$. The average duration of urinary tract catheterisation for the Lap-DP and open-DP group was $2.3 \pm 1.3$ and $3.5 \pm 1.5$ days, respectively, which is a significant intergroup difference $(P=0.0149)$. In the Lap-DP group, no complications, such as pancreatic fistula, were seen. In the open-DP group, three of the 16 patients $(18.8 \%$ ) had complications (pancreatic fistula $n=2$ and ileus $n=1$ ), but there were no significant intergroup differences between the Lap-DP and open-DP groups $(P=0.0784)$. The average postoperative hospital stay for the Lap-DP group was $10.0 \pm 2.6$ days and that for the open-DP group was $25.8 \pm 8.8$ days, and even when excluding the three patients with complications, the average stay was $23.0 \pm 6.4$ days. The average hospital stay for the Lap-DP group was significantly shorter than that for the open-DP group (both $P<0.0001$ ) (Table 3).

Table 4 compares the various clinical parameters among the 20 patients who completed Lap-DP in terms of tumour location $(\mathrm{Pb}$ and $\mathrm{Pt})$. The operating time for the $\mathrm{Pb}$ group was $408.9 \pm 127.0 \mathrm{~min}$, which was significantly longer 
Table 4 Comparison of clinical parameters in Lap-DP based on primary location of pancreatic diseases

\begin{tabular}{|c|c|c|c|}
\hline Demographic-clinical factors & Pancreatic body (eight cases) & Pancreatic tail (12 cases) & $P$ value \\
\hline Age, years ${ }^{\mathrm{a}}$ & $48.4 \pm 22.5$ & $56.9 \pm 15.6$ & $0.3271^{b}$ \\
\hline Sex (male/female) & $3 / 5$ & $3 / 9$ & $0.6424^{\mathrm{c}}$ \\
\hline ASA physical status score ${ }^{a}$ & $1.6 \pm 0.5$ & $1.8 \pm 0.7$ & $0.4897^{\mathrm{b}}$ \\
\hline Body mass index ${ }^{a}$ & $23.6 \pm 3.4$ & $23.3 \pm 2.7$ & $0.8432^{\mathrm{b}}$ \\
\hline Tumour size, centimetres ${ }^{\mathrm{a}}$ & $6.4 \pm 4.6$ & $3.8 \pm 1.8$ & $0.0918^{\mathrm{b}}$ \\
\hline Spleen preservation (no. of patients) & 1 & 6 & $0.1577^{\mathrm{c}}$ \\
\hline Conversion to HAP (no. of patients) & 2 & 3 & $>0.9999^{\mathrm{c}}$ \\
\hline Operation time, minutes ${ }^{\mathrm{a}}$ & $408.9 \pm 127.0$ & $241.5 \pm 65.9$ & $0.0011^{\mathrm{b}}$ \\
\hline Blood loss, millilitres $^{\mathrm{a}}$ & $416.3 \pm 277.6$ & $137.5 \pm 128.1$ & $0.0068^{\mathrm{b}}$ \\
\hline Blood transfusions (no. of patients) & 0 & 0 & $>0.9999^{\mathrm{c}}$ \\
\hline Complications (no. of patients) & 0 & 0 & $>0.9999^{c}$ \\
\hline \multicolumn{4}{|l|}{ HAP, Hand-assisted procedure } \\
\hline
\end{tabular}

than that for the Pt group (241.5 $\pm 65.9 \mathrm{~min} ; P=0.0011)$. In addition, the average blood loss for the $\mathrm{Pb}$ group was $416.3 \pm 277.6 \mathrm{ml}$, which was significantly greater than that for the Pt group $(137.5 \pm 128.1 \mathrm{ml} ; P=0.0068)$. However, there were no statistically significant intergroup differences between BMI and operating time, between BMI and blood loss, between tumour size and operating time, or between tumour size and blood loss (Table 5).

\section{Discussion}

The most noteworthy advantage of laparoscopic surgery is that the cosmetic outcomes are superior because surgical wounds are smaller than those that remain following conventional open surgery. Because the pancreas is located in the retroperitoneum, it must be detached from the dorsal side during pancreatoduodenectomy and distal pancreatectomy as well as partial pancreatectomy and enucleation. Hence, the upper abdominal area must be opened widely. In addition, some pancreatic diseases, such as MCA and SPT, are common in relatively young women, and the cosmetic usefulness of Lap-DP is very high. As a general rule, we emphasise complete laparoscopic resection without conversion to HAP. The main factor influencing this choice of procedure is that with HAP, an incision of at least 7-9 cm must be placed on the front surface of the upper abdomen. With complete laparoscopic surgery, if the spleen is conserved, resected tissue can be removed outside the body by slightly enlarging the area where the trocar is inserted, and even if the spleen is resected with the pancreas, resected tissue can be removed by placing a small incision on the flank region, thus further improving cosmetic outcomes (Fig. 2).
Table 5 Correlations between clinical parameters in Lap-DP

\begin{tabular}{lll}
\hline Clinical parameters & $r$ value & $P$ value \\
\hline BMI vs. operation time & 0.268 & 0.2564 \\
BMI vs. blood loss & 0.371 & 0.1078 \\
Tumour size vs. operation time & 0.086 & 0.7222 \\
Tumuor size vs. blood loss & 0.040 & 0.8704 \\
\hline
\end{tabular}

$r$, Correlation coefficient

Lillimoe et al. [28] studied 235 patients who underwent open-DP at a single institution and reported that the average operating time was $282 \mathrm{~min}$, blood loss was $879 \mathrm{ml}$, total complications were $31 \%$ (pancreatic fistula leakage $5 \%$ ), postoperative hospital stay was 15 days, and perioperative mortality rate was $0.9 \%$. While patients with malignant and benign diseases were included in their study, there were no significant differences between these two groups in terms of operating time, blood loss, hospital stay, and incidence of complications. When compared to the open-DP group in our study, the results are largely comparable, except for postoperative hospital stay. As shown in Table 3, when we compared surgical results between LapDP and open-DP, there were no significant differences in operating time and complications, although blood loss in patients undergoing Lap-DP was significantly lower, thus suggesting that Lap-DP is safer than open-DP. In addition, the time to first passage of flatus after surgery, the duration of urinary tract catheterisation, the time to oral intake, and postoperative stay for the Lap-DP group were significantly more favourable, thus suggesting that Lap-DP is a very useful technique.

Pancreatic fistula is one of the most serious complications of distal pancreatectomy [14, 29-32]. Mabrut et al. 
[14] reviewed a total of 897 patients who underwent openDP and reported the incidence of pancreatic fistula to be $3.5-26 \%$, with an average of $13 \%$. The incidence of pancreatic fistula for Lap-DP in studies involving at least ten patients range from 0 to $27 \%$, and at all institutions, a stapling technique was used when the pancreas was transacted [3, 5-7, 10-12, 14-16, 19, 20, 23, 24]. Studies have reported that pancreatic fistula is likely to occur with a pancreas with a soft texture [14, 29-31], and differences have been seen with respect to resection method [14, 30, 31]. Studies on open-DP have reported the usefulness of ligation of the main pancreatic duct [31] or the necessity of ligating all peripheral narrow pancreatic ducts-not just the main pancreatic duct-using an ultrasonic dissector [30]. However, it was not possible to eliminate pancreatic fistula using any of these methods. With Lap-DP, procedural convenience is important, and pancreatectomy is often performed using a stapling technique. None of the 20 patients had chronic pancreatitis, and all had a soft pancreas. An ELS was used in 19 patients, and none exhibited pancreatic fistula. This may have been due to the appropriate type and size of the stapler. Of 14 studies examining at least ten Lap-DP patients [3, 5-7, 10-12, 14-16, 19, 20, $23,24]$, only five mentioned stapler type and size [6, 10, 20, 23, 24]. Edwin et al. [10] and Palanivelu et al. [24] used the EndoGIA with 4.8-mm staples, which was the same device as that used by us, and reported that pancreatic fistula occurred in none of 17 Lap-DP patients (former study) and in only 1 of 22 Lap-DP patients (latter study), respectively. However, because the number of patients is low at individual hospitals, it will be necessary to conduct a prospective multicentre study.

Surprisingly, the results of the our Lap-DP study did not show that obesity and tumour size correlated to operating time and blood loss. However, when a lesion was in the pancreatic body, operating time and blood loss were significantly greater. When compared to the $\mathrm{Pt}$, the extent of pancreatic detachment from the surrounding retroperitoneal tissue and vessels was greater. Another factor was that the tissue anatomy became complicated near the pancreatic head. In future surgeries, it will be necessary to minimise the differences by further improving procedures and devices. Because Lap-DP will be performed more frequently in the future, it may be necessary to analyse surgical results separately for $\mathrm{Pb}$ and $\mathrm{Pt}$.

\section{Conclusions}

Our initial reasons for performing Lap-DP were cosmetic. Initially, we believed that it would be difficult to develop Lap-DP as a standard technique due to its procedural difficulty. However, the results of our study clearly demonstrate the usefulness of Lap-DP in terms of factors other than cosmetic outcome. In the future, it will be necessary to verify the pancreatectomy stapling technique and to conduct a prospective randomised trial with openDP in order to confirm the usefulness of Lap-DP and then to assess the use of Lap-DP in pancreatic cancer.

\section{References}

1. Gagner M, Pomp A, Herrera MF. Early experience with laparoscopic resections of islet cell tumors. Surgery. 1996;120:1051-4.

2. Cuschieri A, Jakimowicz JJ, Spreeuwel J. Laparoscopic distal $70 \%$ pancreatectomy and splenectomy for chronic pancreatitis. Ann Surg. 1996;223:280-5.

3. Patterson EJ, Gagner M, Salky B, Inabnet WB, Brower S, Edye $\mathrm{M}$, et al. Laparoscopic pancreatic resection: single-institution experience of 19 patients. J Am Coll Surg. 2001;193:281-7.

4. Kano N, Kusanagi H, Yamada S, Kasama K, Ota A. Laparoscopic pancreatic surgery: its indications and techniques: from the viewpoint of limiting the indications. J Hepatobiliary Pancreat Surg. 2002;9:555-8.

5. Park AE, Todd-Heniford B. Therapeutic laparoscopy of the pancreas. Ann Surg. 2002;236:149-58.

6. Fernández-Cruz L, Sáenz A, Astudillo E, Martinez I, Hoyos S, Pantoja JP, et al. Outcome of laparoscopic pancreatic surgery: endocrine and nonendocrine tumors. World J Surg. 2002;26: 1057-65.

7. Fabre JM, Dulucq JL, Vacher C, Lemoine MC, Wintringer P, Nocca D, et al. Is laparoscopic left pancreatic resection justified? Surg Endosc. 2002;16:1358-61.

8. Fernández-Cruz L, Sáenz A, Astudillo E, Pantoja JP, Uzcátegui E, Navarro S. Laparoscopic pancreatic surgery in patients with chronic pancreatitis. Surg Endosc. 2002;16:996-1003.

9. Ammori BJ. Applications of minimally invasive surgery in the management of inflammatory and neoplastic diseases of the pancreas. J Hepatobiliary Pancreat Surg. 2004;11:107-11.

10. Edwin B, Mala T, Mathisen $\varnothing$, Gladhaug I, Buanes T, Lunde OC, et al. Laparoscopic resection of the pancreas. A feasibility study of the short-term outcome. Surg Endosc. 2004;18:407-11.

11. Lebedyev A, Zmora O, Kuriansky J, Rosin D, Khaikin M, Shabtai $\mathrm{M}$, et al. Laparoscopic distal pancreatectomy. Surg Endosc. 2004;18:1427-30.

12. Fernández-Cruz L, Martínez I, Gilabert R, Cesar-Borges G, Astudillo E, Navarro S. Laparoscopic distal pancreatectomy combined with preservation of the spleen for cystic neoplasms of the pancreas. J Gastrointest Surg. 2004;8:493-501.

13. Matsumoto T, Hirano S, Yada K, Himeno Y, Shibata K, Aramaki $\mathrm{M}$, et al. Safety and efficacy laparoscopic distal pancreatectomy for the treatment of pancreatic disease. J Hepatobiliary Pancreat Surg. 2005;12:65-70.

14. Mabrut J-Y, Fernandez-Cruz L, Azagra JS, Bassi C, Delvaux G, Weerts J, et al. Laparoscopic pancreatic resection: results of a multicenter European study of 127 patients. Surgery. 2005; 137:597-605.

15. Ayav A, Bresler L, Brunaud L, Boissel P. Laparoscopic approach for solitary insulinoma: a multicentre study. Langenbecks Arch Surg. 2005;390:134-40.

16. Dulucq JL, Wintringer $P$, Stabilini C, Feryn T, Perissat J, Mahajna A. Are major laparoscopic pancreatic resections worthwhile? A prospective study of 32 patients in a single institution. Surg Endosc. 2005;19:1028-34. 
17. Root J, Nguyen N, Jones B, Mccloud S, Lee J, Nguyen P, et al. Laparoscopic distal pancreatic resection. Am Surg. 2005;71:7449.

18. Mori T, Abe N, Sugiyama M. Atomi Y Laparoscopic pancreatic surgery. J Hepatobiliary Pancreat Surg. 2005;12:451-5.

19. Corcione F, Marzano E, Cuccurullo D, Caracino V, Pirozzi F, Settembre A. Distal pancreas surgery: outcome for 19 cases managed with a laparoscopic approach. Surg Endosc. 2006;20:1729-32.

20. Velanovich V. The lasso technique for laparoscopic distal pancreatectomy. Surg Endosc. 2006;20:1766-71.

21. Uranues S, Alimoglu O, Todoric B, Toprak N, Auer T, Rondon L, et al. Laparoscopic resection of the pancreatic tail with splenic preservation. Am J Surg. 2006;192:257-61.

22. Toniato A, Meduri F, Foletto M, Avogaro A, Pelizzo M. Laparoscopic treatment of benign insulinomas localized in the body and tail of the pancreas: a single-center experience. World J Surg. 2006;30:1-4

23. Pierce RA, Spitler JA, Hawkins WG, Strasberg SM, Linehan DC, Halpin VJ, et al. Outcomes analysis of laparoscopic resection of pancreatic neoplasms. Surg Endosc. 2007;21:579-86.

24. Palanivelu C, Shetty R, Jani K, Sendhilkumar K, Rajan PS, Maheshkumar GS. Laparoscopic distal pancreatectomy, results of a prospective non-randomized study from a tertiary center. Surg Endosc. 2007;22:373-7.

25. Bassi C, Dervenis C, Butturini G, Fingerhut A, Yeo C, Izbicki J, et al. Postoperative pancreatic fistula: an international study group (ISGPF) definition. Surgery. 2005;138:8-13.
26. Pratt W, Maitbel SK, Vanounou T, Callery MP, Vollmer CM. Postoperative pancreatic fistulas are not equivalent after proximal, distal, and central pancreatectomy. J Gastrointest Surg. 2006;10:1264-79.

27. Warshaw AL. Conservation of the spleen with distal pancreatectomy. Arch Surg. 1988;123:550-3.

28. Lillemoe KD, Kaushal S, Cameron JL, Sohn TA, Pitt HA, Yeo CJ. Distal pancreatectomy: indications and outcomes in 235 patients. Ann Surg. 1999;229:693-700.

29. Hamanaka Y, Nishihara K, Hamasaki T, Kawabata A, Yamamoto S, Tsurumi M, et al. Pancreatic juice output after pancreatoduodenectomy in relation to pancreatic consistency, duct size, and leakage. Surgery. 1996;119:281-7.

30. Suzuki Y, Fujino Y, Tanioka Y, Hori Y, Ueda T, Takeyama Y, et al. Randomized clinical trial of ultrasonic dissector or conventional division in distal pancreatectomy for non-fibrotic pancreas. Br J Surg. 1999;86:608-11.

31. Bilimoria MM, Cormier JN, Mun Y, Lee JE, Evans DB, Pisters PWT. Pancreatic leak after left pancreatectomy is reduced following main pancreatic duct ligation. Br J Surg. 2003;90:190-6.

32. Kuroki T, Tajima Y, Kanematsu T. Surgical management for the prevention of pancreatic fistula following distal pancreatectomy. J Hepatobiliary Pancreat Surg. 2005;12:283-5. 